\title{
The Use of Focus-Variation Microscopy for the Assessment of Active Surfaces of a New Generation of Coated Abrasive Tools
}

\author{
Wojciech Kapłonek ${ }^{1}$, Krzysztof Nadolny², Grzegorz M. Królczyk ${ }^{3}$ \\ ${ }^{I}$ Subject Group of Metrology and Quality, Department of Production Engineering, Faculty of Mechanical Engineering, \\ Koszalin University of Technology, Ractawicka 15-17, 75-620 Koszalin, Poland \\ ${ }^{2}$ Department of Production Engineering, Faculty of Mechanical Engineering, Koszalin University of Technology, \\ Racławicka 15-17, 75-620 Koszalin, Poland, krzysztof.nadolny@tu.koszalin.pl \\ ${ }^{3}$ Faculty of Mechanical Engineering, Opole University of Technology, Prószkowska 76, 45-758 Opole, Poland
}

\begin{abstract}
In this paper, the selected results of measurements and analysis of the active surfaces of a new generation of coated abrasive tools obtained by the use of focus-variation microscopy (FVM) are presented and discussed. The origin of this technique, as well as its general metrological characteristics is briefly described. Additionally, information regarding the focus variation microscope used in the experiments - InfiniteFocus ${ }^{\circledR}$ IF G4 produced by Alicona Imaging, is also given. The measurements were carried out on microfinishing films (IMFF), abrasive portable belts with Cubitron ${ }^{\mathrm{TM}}$ II grains, and single-layer abrasive discs with Trizact ${ }^{\mathrm{TM}}$ grains. The obtained results were processed and analyzed employing TalyMap 4.0 software in the form of maps and profiles, surface microtopographies, AbbottFirestone curves, and calculated values of selected areal parameters. This allowed us to describe the active surfaces of the coated abrasive tools, as well as to assess the possibility of applying the FVM technique in such kinds of measurements.
\end{abstract}

Keywords: Focus-variation microscopy, coated abrasive tools, Cubitron ${ }^{\mathrm{TM}}$ II, Trizact $^{\mathrm{TM}}$, IMFF.

\section{INTRODUCTION}

The condition of the active surface of abrasive tools is an important factor determining the proper course and obtained results of the machining process. The detection of dulled abrasive grain vertexes, as well as the location and analysis of clogging areas of the workpiece material must be properly assessed. Issues regarding the broadly defined assessment of abrasive tools have been extremely important for many years, as has been demonstrated by Wang and Gao, as well as Wegener et al. in numerous works from this field $[1,2]$. In many such works, the various measuring methods that may be used in this type of assessment are listed. Moreover, their authors emphasize the significant limitation of stylus methods in relation to the assessment of abrasive tools and, in this case, suggest optical methods as those which are most preferred. From the relatively broad group of such methods, the following are very promising in this field: optical profilometry (OP) [3], white-light interferometry (WLI) and its numerous variations [4], scanning electron microscopy (SEM) [5], confocal microscopy (CM) [6], as well as focus-variation microscopy (FVM) [7].

The last of these techniques will be presented in slightly more detail in this paper in the context of the possibilities of using it in non-contact measurements and analysis of the active surfaces of modern coated abrasive tools such as: Imperial ${ }^{\mathrm{TM}}$ Microfinishing Films (IMFF), Cubitron ${ }^{\mathrm{TM}}$ II and Trizact ${ }^{\mathrm{TM}}$.

The experimental part of the work (Section 3 ) is preceded by a brief discussion of the origin of the method, the principles of measurement, the construction and operation of the measurement instrument and its applications in the field of abrasive machining (Section 2). In the final part, the exemplary results obtained for an assessed group of modern coated abrasive tools during the experiments carried out, as well as important observations arising from the used measurement system in the form of detailed conclusions, are given (Section 4).

\section{CHARACTERISTICS OF THE FOCUS-VARIATION MICROSCOPY}

In recent years there has been particularly rapid development of new measuring techniques based on light microscopy. This applies especially to modern varieties of confocal microscopy, such as confocal laser scanning microscopy (CLSM) [8-10], and the relatively new technique of focusvariation microscopy (FVM). This technique, similar to confocal microscopy, uses the ideas of image acquisition based on an analysis of the depth of field - focus variation, whose principles were developed by $\mathrm{H}$. von Helmholtz [11] 
in the mid-1920s. However, the first modern research works related to the development basis of a new measurement technique, as well as the design and construction of the focus variation instrument, began in the early 1990s. Some of these early experiments were described in one chapter of a work by R. Leach [12], as well as by F. Helmli [13] and F. Helmli, R. Danzl, M. Prantl, M. Grabner and S. Scherer [14,15].

At the beginning of the 21 st century, the first commercially produced focus variation instruments have begun to appear. In Europe, the most popular are those from the Infinite Focus ${ }^{\circledR}$ family offered by Alicona Imaging (Austria).

The principle of operation of such instrument, presented in Fig.1., is based on the projection of a beam of light on a relatively small area of the surface of the assessed object.
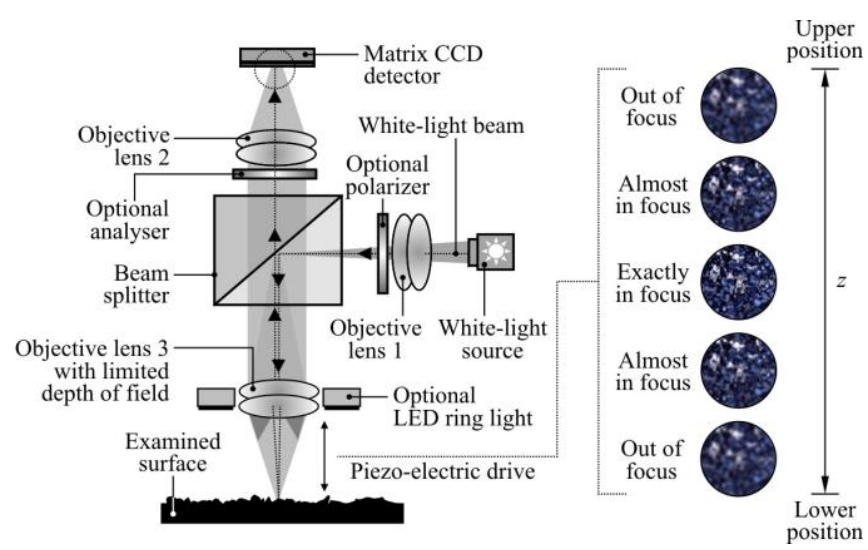

Fig.1. Schematic diagram showing the principle of operation of typical focus variation instrument and the method for measurement of the selected features (e.g., surface roughness) of examined surfaces based of focus-variation effect.

The light reflected from the surface returns to the optical system of the microscope and is directed by a beam splitter onto the active area of the photoelectric detector, where it forms an image containing information of a photometric (color, brightness, contrast) and geometric character (length, width) [16]. The processing signal unit searches only for those parts of the image on which a beam of light has been focused. These parts will be then reconstructed and a final 3D. image will be generated. In order to obtain a surface micro- topography, it is necessary to carry out the scan process in the $z$ axis. For each of the positions in this axis, the focus variation $\left(F_{z}\right)$ calculated as a standard deviation of the grey values of a small local region is measured from the equation proposed by F. Helmli in the work [13] and given below:

$$
F_{z}(x, y)=F M\left(\operatorname{reg}_{w}\left(I_{z}(x, y)\right)\right)
$$

where:

$$
F M=\frac{1}{n^{2}} \sum_{r e g_{w}\left(I_{z}, x, y\right)}\left(G V_{i}-\overline{G V}\right)^{2}
$$

where: $F M$ - focus measure [17], $\operatorname{reg}_{w}\left(I_{z}(x, y)\right)$ - local region of the image $I_{z}(x, y), G V_{i}$ - grey value of the $i$-th pixel, $\overline{G V}$ - average grey value of $\operatorname{reg}_{w}\left(I_{z}(x, y)\right), n$ - number of involved pixels.

The process is performed by the precise movement of the column with a set of dedicated microscopic lenses in the $z$-axis, measured from the lowest to the highest point of the surface while maintaining adequate focus. Finally, as a result of the relatively short scan process, a large number of points are obtained which allows one to achieve high resolution measurements [18].

In Fig.2. a general view of the focus variation microscope InfiniteFocus ${ }^{\circledR}$ IF G4 by Alicona Imaging is presented.

The measuring range of a typical variation focus instrument is in a range from approx. $3 \mathrm{~mm}$ to $20 \mathrm{~mm}$ at the vertical resolution $10 \mathrm{~nm}$ and $400 \mathrm{~nm}$, respectively (depending on the instrument). It is worth emphasizing that the obtained image (as a result of the reconstruction) is saved in its true colors and not indexed, an aspect which is undoubtedly an advantage of this technique. However, its disadvantages include some limitations in the measurement of surfaces characterized by high angles of slope (more than $85^{\circ}$ ), large heights of irregularities (some machined surfaces, abrasive tools), smooth and super-smooth surfaces characterized by low and very low heights of irregularities (hard disc platters, opto-electronic components), transparent and semi-transparent surfaces (silicon wafers, glass) as well as a lower resolution of obtained measurement data with relation to the CLSM. and WLI. Other problems, e.g., with calibration of the

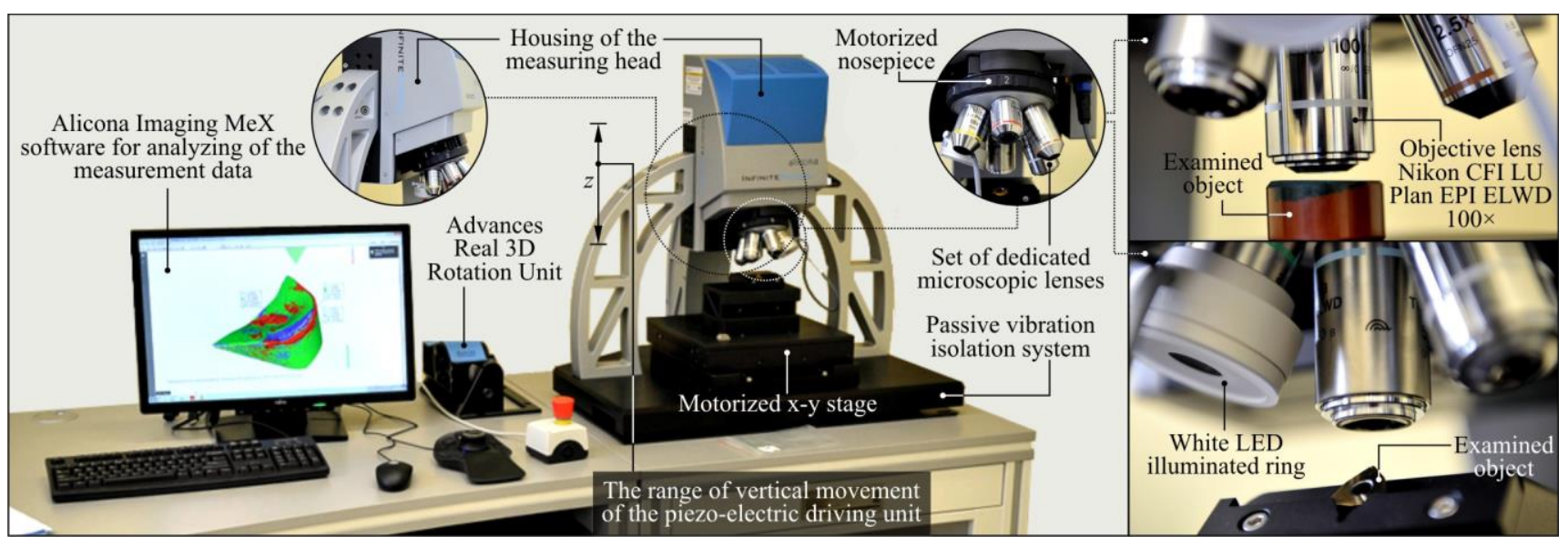

Fig.2. General view of the focus variation microscope InfiniteFocus ${ }^{\circledR}$ IF G4 produced by Alicona Imaging used in the experimental investigations. 
instruments before the measurement process (in the context of estimating the measurement noise and residual flatness deviation) have been described in detail in the work of Giusca et al. [19], while the examination of sensitivity of the focusing variation on the angle of slope of the surface by using areal parameters of the surface roughness has been discussed in the work of Hiersemenzel et al. [20].

Due to its metrological features, FVM can complement stylus methods (if they can be used in a given measurement task) or various methods from the optical group and selected coordinate-measuring techniques. This facilitates, among others, the ISO standardization prepared for focus variation instruments according to the document [21].

FVM is not only relatively new but includes the most dynamically developing measurement techniques of the last several years. Application of these techniques in a number of modern scientific and technological fields can be found in the literature [22-25]. Moreover, in abrasive machining technologies many applications occur that relate to the assessment of the condition of the machined surface [26-29] and the condition of the abrasive tool's active surface [30-33].

\section{EXPERIMENTAL INVESTIGATIONS}

The main goal of this experimental work was to assess the possibility of applying FVM in relation to the measurement and analysis of the active surfaces of a new generation of coated abrasive tools. In addition, the authors tested the metrological capabilities of the instrument used (Alicona Imaging InfiniteFocus ${ }^{\circledR}$ IF G4) during its assessment of coated abrasive tools which are relatively complicated regarding measurements.

\section{A. The samples}

For the experimental investigations, a set of three samples in the form of coated abrasive tools was selected:

- elastic microfinishing films - type IMFF 5MIL 272L with aluminum oxide grains,

- abrasive portable belts with Cubitron ${ }^{\mathrm{TM}}$ II 984F grains,

- single-layer abrasive discs with Trizact ${ }^{\mathrm{TM}}$ grains

All abrasives were produced by $3 \mathrm{M}$ (USA). Their general characteristics are presented in Table 1.

\section{B. Measurement instrument}

The examination of surface samples was carried out by employing the InfiniteFocus ${ }^{\circledR}$ IF G4 focus variation microscope, produced by Alicona Imaging. The lateral travel range ( $x-y$ axes) of the instrument was $100 \times 100 \mathrm{~mm}$, whereas the vertical travel range (z-axis) was $100 \mathrm{~mm}$. The IF G4 was equipped with a motorized nosepiece using a set of five dedicated microscopic objective lenses characterized in Table 2. White light was provided to the objective lenses by an optical fiber from external regulated source $\mathrm{DCR}^{\circledR}$ III illuminator produced by Schott AG (Germany). The motorized nosepiece was additionally equipped with a white LED illuminating ring. The possibility of carrying out measurements of large surface areas using an image stitching procedure was realized by motorized microscope $x$ $y$ stage, H128V3 produced by Prior Scientific (United Kingdom).
Table 1. General characteristics of the coated abrasive tools assessed during experimental investigations.

\begin{tabular}{|c|c|c|c|c|c|}
\hline $\mathbf{S}^{\mathbf{1})}$ & $\begin{array}{c}\text { Abrasive } \\
\text { tool }^{2)}\end{array}$ & $\begin{array}{l}\text { Trade } \\
\text { name }\end{array}$ & Material & Grit & $\begin{array}{c}\text { Grain } \\
\mu \mathrm{m}\end{array}$ \\
\hline F1 & \multirow{5}{*}{$\begin{array}{l}\text { Elastic } \\
\text { micro- } \\
\text { finishing } \\
\text { film }\end{array}$} & \multirow{5}{*}{ IMFF } & \multirow{5}{*}{$\begin{array}{l}\text { Alu- } \\
\text { minum } \\
\text { oxide }\end{array}$} & 1200 & 9 \\
\hline $\mathrm{F} 2$ & & & & 600 & 15 \\
\hline F3 & & & & 400 & 30 \\
\hline F4 & & & & 220 & 60 \\
\hline F5 & & & & 180 & 80 \\
\hline $\mathrm{C} 1$ & \multirow{2}{*}{$\begin{array}{l}\text { Abrasive } \\
\text { portable } \\
\text { belt }\end{array}$} & \multirow{2}{*}{$\begin{array}{l}\text { Cubi- } \\
\text { tron } \\
\text { TM II } \\
984 \mathrm{~F}\end{array}$} & \multirow{2}{*}{\multicolumn{2}{|c|}{$\begin{array}{c}\text { Prec.-shaped } \\
\text { sub-micro- } \\
\text { crystalline } \\
\text { sintered alumina }\end{array}$}} & \multirow[b]{2}{*}{ N/A ${ }^{3)}$} \\
\hline $\mathrm{C} 2$ & & & & & \\
\hline $\mathrm{T} 1$ & \multirow{7}{*}{$\begin{array}{l}\text { Single- } \\
\text { layer } \\
\text { abrasive } \\
\text { disc }\end{array}$} & \multirow{7}{*}{$\begin{array}{c}\text { Triza- } \\
\text { ct }^{\mathrm{TM}}\end{array}$} & \multirow{7}{*}{$\begin{array}{l}\text { Micro- } \\
\text { crystalline } \\
\text { sintered } \\
\text { alumina }\end{array}$} & $\begin{array}{c}\mathrm{A} 6 \\
(\mathrm{P} 2000)^{4)}\end{array}$ & 7.5 \\
\hline $\mathrm{T} 2$ & & & & $\begin{array}{c}\text { A16 } \\
(\mathrm{P} 1200)^{4)}\end{array}$ & 15 \\
\hline T3 & & & & $\begin{array}{c}\mathrm{A} 30 \\
(\mathrm{P} 600)^{4)}\end{array}$ & 25.8 \\
\hline $\mathrm{T} 4$ & & & & $\begin{array}{c}\mathrm{A} 45 \\
(\mathrm{P} 400)^{4)}\end{array}$ & 35 \\
\hline T5 & & & & $\begin{array}{c}\text { A65 } \\
(\mathrm{P} 280)^{4)}\end{array}$ & 53 \\
\hline T6 & & & & $\begin{array}{c}\mathrm{A} 100 \\
(\mathrm{P} 180)^{4)}\end{array}$ & 78 \\
\hline $\mathrm{T} 7$ & & & & $\begin{array}{c}\mathrm{A} 160 \\
(\mathrm{P} 120)^{4)}\end{array}$ & 127 \\
\hline
\end{tabular}

1) Sample designation, ${ }^{2)}$ Manufactured by $3 \mathrm{M}$ (USA), ${ }^{3)}$ Grain is not specified according to FEPA (Federation of European Producers of Abrasives), ${ }^{4)}$ Grite equivalents by FEPA

Table 2. General characteristics of objective lenses used in motorized nosepiece of Alicona Imaging InfiniteFocus ${ }^{\circledR}$ IF G4.

\begin{tabular}{|c|c|c|c|c|}
\hline $\begin{array}{c}\text { Objective lens } \\
\text { type }^{1)}\end{array}$ & Mag. & NA & $\begin{array}{c}\text { WD, } \\
\mathbf{m m}\end{array}$ & $\begin{array}{c}\text { FOV } \boldsymbol{x} \times \boldsymbol{y}, \\
\mathbf{m m}\end{array}$ \\
\hline CFI L Plan EP $^{2)}$ & $2.5 \times$ & 0.07 & 8.80 & $7.145 \times 5.437$ \\
\hline CFI LU Plan EPI $^{2)}$ & $10 \times$ & 0.30 & 17.30 & $1.429 \times 1.088$ \\
\hline \multirow{2}{*}{$\begin{array}{c}\text { CFI LU Plan EPI } \\
\text { ELWD }^{3)}\end{array}$} & $20 \times$ & 0.40 & 13.00 & $0.715 \times 0.544$ \\
\cline { 2 - 5 } & $50 \times$ & 0.55 & 10.10 & $0.286 \times 0.218$ \\
\cline { 2 - 5 } & $100 \times$ & 0.80 & 3.50 & $0.109 \times 0.15$ \\
\hline
\end{tabular}

1) Objective lenses produced by Nikon (Japan) ${ }^{2)}$ Standard-type (achromat) objective lens, ${ }^{3)}$ Long working distance objective lens. Mag. - magnification, NA - numerical aperture, WD - working distance, FOV - field of view

On the stage, samples with maximum height of up to $240 \mathrm{~mm}$ and maximum weight of up to $20 \mathrm{~kg}$ can be examined.

For the measurements, samples in the form of a rectangle $50 \times 20 \mathrm{~mm}$ (for materials described in subsection A) were prepared. The surface microtopographies of each sample were measured in order to obtain detailed views (a small surface area: $\leq 1.5 \times 1.5 \mathrm{~mm}$ ), as well as to obtain a view of the surface in a more general (wide) view. In this case, a large surface area $(\geq 2.0 \times 2.0 \mathrm{~mm})$ was registered using an image stitching procedure [34]. The measurement time for individual samples depended on the type of surface and its specific 
characteristics, as well as the registration parameters adopted for the instrument. Generally, the measurement time ranged from tens of seconds to a few minutes.

\section{Processing and analysis of the measurement data}

The InfiniteFocus ${ }^{\circledR}$ IF G4 focus variation microscope was supported by advanced MeX 6.1 software produced by Alicona Imaging [35]. The data obtained from the instrument was saved in *.AL3D format and next converted to the more universal *.SUR format. However, the authors decided that a full analysis of the measurement data would be carried out employing TalyMap Platinum 4.0 software produced by DigitalSurf (France). The sequence of data preprocessing in this software included the following steps: opening of the obtained measurement data, leveling (least square (LS) plane method) and filling in non-measured points. A proper analysis was carried out on the basis of selected studies offered by the software: a surface map in indexed colors, where the height of the surface elements was encoded with the color, a photo simulation, a contour diagram (color background mode), a profile and a surface microtopography, an Abbott-Firestone curve and a graphical study of $S k$ parameters, as well as calculated values of selected parameters from the amplitude, spatial, hybrid and functional groups, as described in Table 3.

Table 3. The general characteristics of calculated parameters describing the surface of assessed coated abrasive tools.

\begin{tabular}{|c|c|c|}
\hline Group & Parameter & Name \\
\hline \multirow{7}{*}{ Amplitude ${ }^{1)}$} & $S a$ & $\begin{array}{l}\text { Arithmetic mean deviation } \\
\text { of the surface }\end{array}$ \\
\hline & $S t$ & Total height of the surface \\
\hline & $S q$ & $\begin{array}{l}\text { Root-Mean-Square (RMS) } \\
\text { deviation of the surface }\end{array}$ \\
\hline & $S p$ & Maximum height of summits \\
\hline & Sv & Maximum depth of valleys \\
\hline & Ssk & $\begin{array}{l}\text { Skewness of the height } \\
\text { distribution }\end{array}$ \\
\hline & Sku & $\begin{array}{l}\text { Kurtosis of the height } \\
\text { distribution }\end{array}$ \\
\hline Spatial ${ }^{1)}$ & $S d s$ & $\begin{array}{l}\text { Density of summits of the } \\
\text { surface }\end{array}$ \\
\hline Hybrid ${ }^{1)}$ & $S d q$ & $\begin{array}{l}\text { Root-Mean-Square slope of } \\
\text { the surface }\end{array}$ \\
\hline \multirow{3}{*}{ Functional ${ }^{2)}$} & $V m p$ & Material volume of peaks \\
\hline & $V m c$ & Material volume of the core \\
\hline & $V v v$ & Void volume of valleys \\
\hline
\end{tabular}

1) Parameters are included in the ISO 25178-2:2012 standard [36] and EUR 15178 EN report [37], ${ }^{2)}$ Parameters defined in the report of the European program SURFSTAND [38]

An exemplary analysis of selected results obtained for the active surface of coated abrasive tools by the InfiniteFocus ${ }^{\circledR}$ IF G4 focus variation microscope during experimental investigations is presented in Fig. 3 - Fig.5.

A collection of results obtained for the active surface of elastic microfinishing film, type IMMF produced by 3M, represented by the samples F1 - IMFF 1200 (grain size $9 \mu \mathrm{m}$ ) and F5 - IMFF 180 (grain size $80 \mu \mathrm{m}$ ), is presented in
Fig.3. The sequence of analyses includes the following studies: surface maps in indexed colors with marked lines for which the profiles were determined, as well as photo simulations and surface microtopographies. The analyses were preceded by a SEM micrograph (size $64.27 \times 48.29 \mu \mathrm{m}$, mag. 2000x) of the active surface of IMFF 8000 (grain size $1 \mu \mathrm{m})$ acquired by a JSM-5500 LV scanning electron microscope produced by JEOL (Japan). The structure of this coated abrasive tool in a wide view was clearly visible. On the surface, typical microfinishing film elements, such as abrasive agglomerates, resin bond and fragments of polyester film, were observed. Abrasive agglomerates are randomly connected together, forming a strong and compact structure.

A fragment of the active surface of sample F1 - IMFF 1200 is presented in Fig.3.b). The relatively small area (size $0.50 \times 0.50 \times 0.02 \mathrm{~mm}$ ) of the analysis makes it possible to observe a characteristic abrasive agglomerate-based structure. Agglomerates form narrow steep sidewalls and slightly rounded vertexes, what can be observed on the surface profile. Moreover, areas of resin bond and polyester film are clearly visible on the surface microtopography. In this case, the nominal abrasive grain size is $9 \mu \mathrm{m}$, which affects the values of areal parameters (amplitude). These values are as follows: $S a=3.35 \mu \mathrm{m}, \quad S q=4.16 \mu \mathrm{m}$, $S p=14.7 \mu \mathrm{m}, S v=11 \mu \mathrm{m}$ and $S t=25.8 \mu \mathrm{m}$.

Fig.3.c) presents a fragment of the active surface of sample F5 - IMFF 180. The measured area was significantly larger in order to demonstrate the surface in more general (wide) view. In order to obtain such a surface microtopography, an image stitching procedure offered by the TalyMap Platinum software was used. This procedure was carried out by the use of Visual Basic script Advances DataStiching 1.2.1 [39]. Such stitched-surface microtopography (size $2.85 \times 2.16 \times 0.23 \mathrm{~mm}$ ) was characterized by the following values of areal parameters (amplitude): $\quad S a=21.2 \mu \mathrm{m}, \quad S q=27.5 \mu \mathrm{m}, \quad S p=135 \mu \mathrm{m}$, $S v=96.9 \mu \mathrm{m}$ and $S t=232 \mu \mathrm{m}$. Although they are higher than those obtained for sample F1, it must be remembered that they have been determined for an area which is nearly five times larger.

The samples obtained from abrasive portable belts with Cubitron $^{\mathrm{TM}}$ II abrasive grains, designated $\mathrm{C} 1$ and $\mathrm{C} 2$, respectively, are presented in Fig.4. The individual Fig.4.a) b) relate to two fragments of the same active surface (size $2.85 \times 2.16 \times 0.57-0.66 \mathrm{~mm}$ ). Regardless of the fragment of the analyzed surface, their large diversity was clearly visible. In such surfaces three layers can be distinguished, comprising sequentially: abrasive grains, bond, and elastic base. The triangular-shaped abrasive grains, characterized by self-sharpening properties, are randomly localized on the surface of the abrasive tool. Their morphology is presented in surface visualizations. Some of the visible grains are properly technologically formed - they have steep sidewalls and sharpened vertexes. Others have partially dulled or slightly rounded vertexes. Few of them are strongly defected and practically devoid of their cutting ability. For the two surface microtopographies presented in Fig.4., a set of areal parameters (amplitude) were calculated. The obtained values, in both cases (Fig.4.a).-.b)), are on average three times higher than those obtained for samples F1 - IMFF 1200 and F5 - IMFF 180. At the bottom of Fig.4., the two 
surface profiles extracted from surface microtopographies are presented. The sidewalls of marked single abrasive grains are sloped in relation to the surface at angles ranging from $40^{\circ}$ to $50^{\circ}$.

The collection of results obtained for the active surface of single-layer abrasive discs with Trizact $^{\mathrm{TM}}$ abrasive grains is presented in Fig.5. An SEM micrograph, taken from [40], shows the characteristic regular pyramid-like structure of this abrasive tool (Fig.5.a)). It may be a good point to make a study of its morphology and gain a reference for comparison with surface microtopographies. The sequence of obtained data for sample T3 - A30 (grain size $25.8 \mu \mathrm{m}$ ) and sample T7 - A160 (grain size $160 \mu \mathrm{m}$ ) are presented in Fig.5.b) - c).

Surface profiles were extracted from two of the surface maps (size $2.0 \times 2.0 \mathrm{~mm}$ ). They are useful for analyzing the shape of individual grains, as well as for determining the surface profiles extracted from two of the surface maps (size $2.0 \times 2.0 \mathrm{~mm}$ ). They are useful for analyzing the shape of individual grains, as well as for determining the slope angle of the sidewalls. In this case, the angles are in a range of $30^{\circ}-50^{\circ}$. Surface microtopographies (size $2.0 \times 2.0 \times 0.35$ $0.46 \mathrm{~mm}$ ) were used for calculation of the selected areal parameters (amplitude). For sample T3 they were as follows: $\quad S a=69.40 \mu \mathrm{m}, \quad S q=82.10 \mu \mathrm{m}, \quad S p=205 \mu \mathrm{m}$, $S v=144 \mu \mathrm{m}$ and $S t=350 \mu \mathrm{m}$, whereas for sample T7 they were: $S a=97.60 \mu \mathrm{m}, S q=115 \mu \mathrm{m}, S p=269 \mu \mathrm{m}, S v=195 \mu \mathrm{m}$ and $S t=464 \mu \mathrm{m}$. The calculated values for $\mathrm{T} 7$ were approximately $30 \%$ higher than for T3. In relation to other samples, the average values of parameters obtained for Trizact $^{\mathrm{TM}}$ abrasive grains were in general at this same level (Cubitron $^{\mathrm{TM}}$ ) or three times higher (IMFF).

As a supplement to the analyses from Fig.3. - Fig.5 for the selected samples, F2, C1 and T3 surfaces (size 2.0×2.0 mm), the coated abrasive tools, an Abbott-Firestone curve with graphical studies of $S k$ parameters was determined (Fig.6.). Additionally, for these same samples the values of amplitude, spatial, hybrid and functional parameters were calculated and are given in Table 4.

The Abbot-Firestone curve describes the bearing ratio curve (BRC), which determines the percentage of material traversed in relation to the area covered for a given depth. The vertical axis presents the depths (in $\mu \mathrm{m}$ and $\mathrm{mm}$ ), whereas the horizontal axis presents the bearing ratio (in \%). The AbbotFirestone curve is often coupled with a depths histogram, which is very useful in analyzing the surface texture of the coated abrasive tools being assessed. Moreover, a depths histogram describes the density of the distribution of the data points in the assessed profile.

A visual analysis of depths histograms, as well as AbbottFirestone curves (Fig.6.), obtained for the analyzed surfaces indicates that samples F2 - IMMF 600 (grain size $15 \mu \mathrm{m}$ ) and $\mathrm{C} 1-60+$ (grain size N/A) have a similar course. It should be noted, however, that the values obtained for sample C1 $\left(S k_{(\mathrm{C} 1)}=220 \mu \mathrm{m}\right)$ are the highest, which confirms the graphical studies of $S k$ parameters, whereas F2 $\left(S k_{(\mathrm{F} 2)}=12 \mu \mathrm{m}\right)$ was the lowest. This low value means that the surface of sample F2 was strongly smoothed. For sample T3 - A30 (grain size $25.8 \mu \mathrm{m}$ ), the depths histogram, as well as the Abbott-Firestone curve have different shape, indicating a higher angle of slope of the peaks occurring on this surface.
The analysis of values obtained for these same samples, presented in Table 4., confirms earlier insights. The highest values of amplitude parameters $S a$ and $S q$ were calculated for samples $\mathrm{C} 1$ and T3. The values were approx. 17.5 times higher than the values obtained for F2, which was caused primarily by the grain size of the analyzed tools, influencing parameters for the total height of the surface $\left(S t_{(\mathrm{C} 1)}=570\right.$ $\left.660 \mu \mathrm{m}, S t_{(\mathrm{T} 3)}=300-460 \mu \mathrm{m}, S t_{(\mathrm{F} 2)}=20-270 \mu \mathrm{m}\right)$. The positive sign of the $S s k$ parameter indicates the predominance of peaks comprising the surface, whereas $S k u$ indicates the presence of inordinately high peaks/deep valleys on the surface. The values of $S s k$ parameter were in a range of $0.41-0.55 \mu \mathrm{m}$. The lowest value of the $S s k$ parameter was obtained for sample T3 $\left(S s k_{(\mathrm{T} 3)}=0.41\right)$, which means that its surface was more homogeneous regarding the occurrence of high peaks/deep valleys. The values of the $S k u$ parameter were in a range of 3.26-3.58, which means that all surfaces were characterized by the occurrence of high peaks/deep valleys. The highest value of spatial parameter $S d s$ was observed for sample F2 $\left(S d s_{(\mathrm{F} 2)}=241 \mathrm{pks} / \mathrm{mm}^{2}\right)$. This value was 2 times higher than the value obtained for sample $\mathrm{C} 1$ $\left(S d s_{(\mathrm{Cl})}=121 \mathrm{pks} / \mathrm{mm}^{2}\right)$ and more than 3 times higher than the value obtained for sample T3 $\left(S d s_{(\mathrm{T} 3)}=76.7 \mathrm{pks} / \mathrm{mm}^{2}\right)$. The lowest value of the hybrid parameter $S d q$ was obtained for sample F2 $\left(S d q_{(\mathrm{F} 2)}=1.25\right)$, whereas for samples $\mathrm{C} 1$ and T3, similar values $\left(S d q_{(\mathrm{C} 1)}=1.86, \quad S d q_{(\mathrm{T} 3)}=1.81\right)$ were observed. These high values indicate that these surfaces are characterized by a higher angle of slope of the peaks than the surface of sample F2. In analyzing the Abbott-Firestone curves and the associated functional parameters, it can be observed that the measurement method had the slightest influence on one of them $-V v v$. For sample F2 the value of the material volume of peaks $\left(V m p_{(\mathrm{F} 2)}=0.002 \mathrm{~mm}^{3} / \mathrm{mm}^{2}\right)$ was approximately 15 times lower than the value of material volume of the core $\left(V m c_{(\mathrm{F} 2)}=0.013 \mathrm{~mm}^{3} / \mathrm{mm}^{2}\right)$, whereas this same relationship observed for sample T3 was approx. 3.5 times lower. This means that the surface of sample F2 had been more smoothed than the surface of sample T3.

The experimental investigations carried out were also a good opportunity for testing the metrological capabilities of the measurement instrument used. The authors pay particular attention both to the metrological parameters related to the measurements carried out, the ease and intuitiveness of the measurement process, as well as the broad possibilities of proper data processing and analysis. Additionally, an important aspect that was studied was the accuracy of the measurement data obtained in relation to the measurement of the active surfaces of selected coated and bonded abrasive tools. The experience gained during the measurements of the above-mentioned tools by using one of the FVM techniques allowed us, in a subjective way, to compare their measurement possibilities with other optical techniques (which were widely used during previously performed experiments). An overview of compared optical techniques is given in Table 5. Indeed, an analysis of this table leads to the conclusion that the use of WLI in assessing the active surfaces of abrasive tools gives the best results, CLSM produces relatively good results, whereas OP and FVM rather give average results. However, while these techniques can be used in the above applications, they require more care in the selection of measurement parameters. 


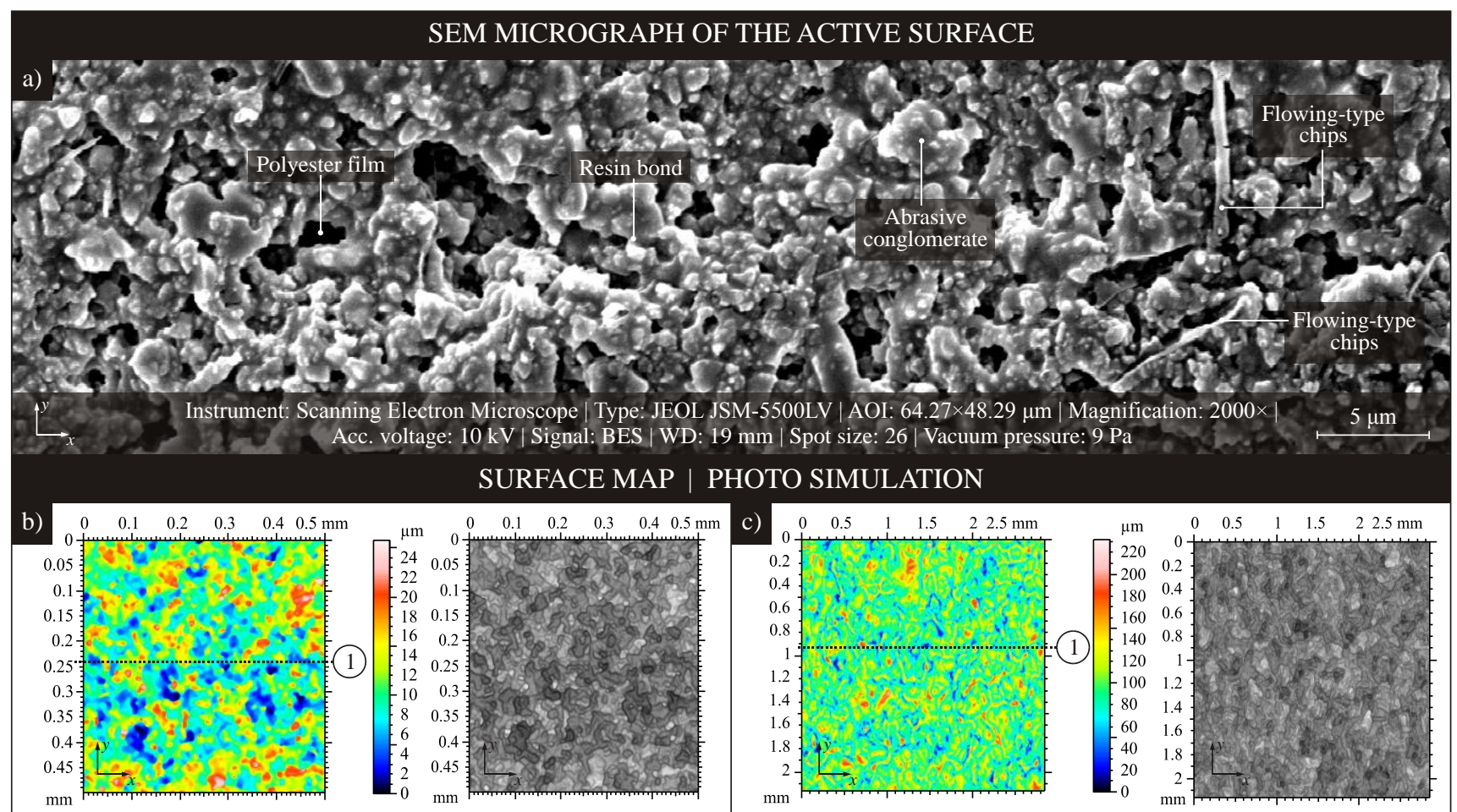

SURFACE ROUGHNESS PROFILE
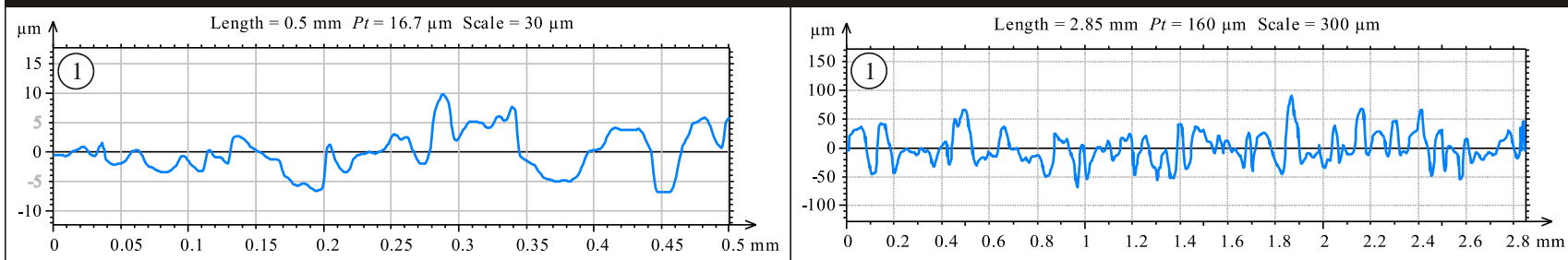

\section{SURFACE MICROTOPOGRAPHY}

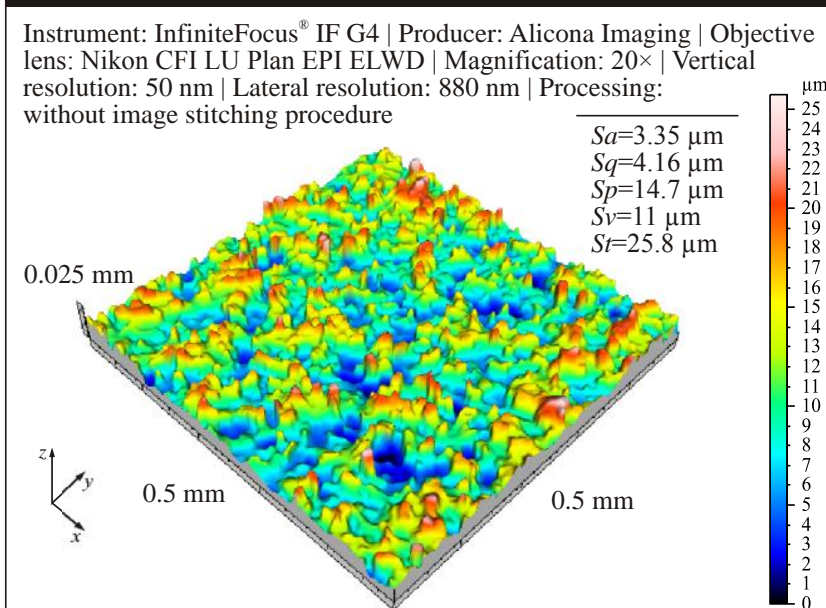

Area of a single topography (axes $x, y, z): 0.50 \times 0.50 \times 0.025 \mathrm{~mm} \mid$ The num of profile points (axis $x$ ): 569 | Distance between profile points (axis $x$ ): $0.88 \mu \mathrm{m} \mid$ The number of profiles (axis $y$ ): 568

Distance between profile points (axis $y): 0.88 \mu \mathrm{m}$
Instrument: InfiniteFocus ${ }^{\circledR}$ IF G4 | Producer: Alicona Imaging | Objective lens: Nikon CFI LU Plan EPI ELWD | Magnification: $20 \times \mid$ Vertical resolution: $50 \mathrm{~nm}$ | Lateral resolution: $880 \mathrm{~nm}$ | Processing: with image stitching procedure (matrix $4 \times 4$ )

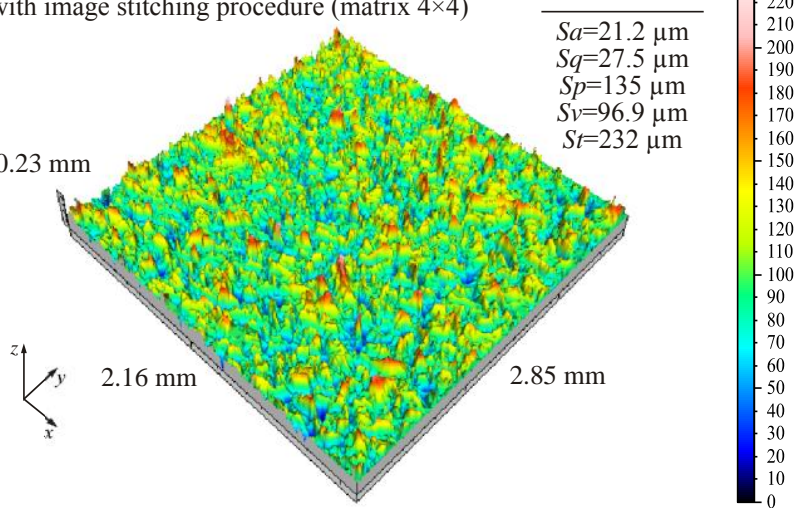

Area of a single topography (axes $x, y, z): 2.85 \times 2.16 \times 0.23 \mathrm{~mm} \mid$ The number of profile points (axis $x$ ): $814 \mid$ Distance between profile points (axis $x$ ): $3.51 \mu \mathrm{m} \mid$ The number of profiles (axis y): 618 Distance between profile points

Fig.3. Collection of select results of experimental tests carried out for active surface of elastic microfinishing film type IMMF produced by $3 \mathrm{M}$, obtained by use of focus variation microscope InfiniteFocus ${ }^{\circledR}$ IF G4 produced by Alicona Imaging: a) SEM micrograph (size: $64.27 \times 48.29 \mu \mathrm{m}$, mag. 2000×) acquired by scanning electron microscope JSM-5500 LV produced by JEOL (Japan), presenting a vast panorama of the active surface of IMFF 8000 (grain size: $1 \mu \mathrm{m}$ ) with its characteristic elements, $b$ ) sequence of results obtained for sample F1 - IMFF 1200 (grain size: $9 \mu \mathrm{m}$ ), c) sequence of results obtained for sample F5 - IMFF 180 (grain size: $80 \mu \mathrm{m}$ ). 


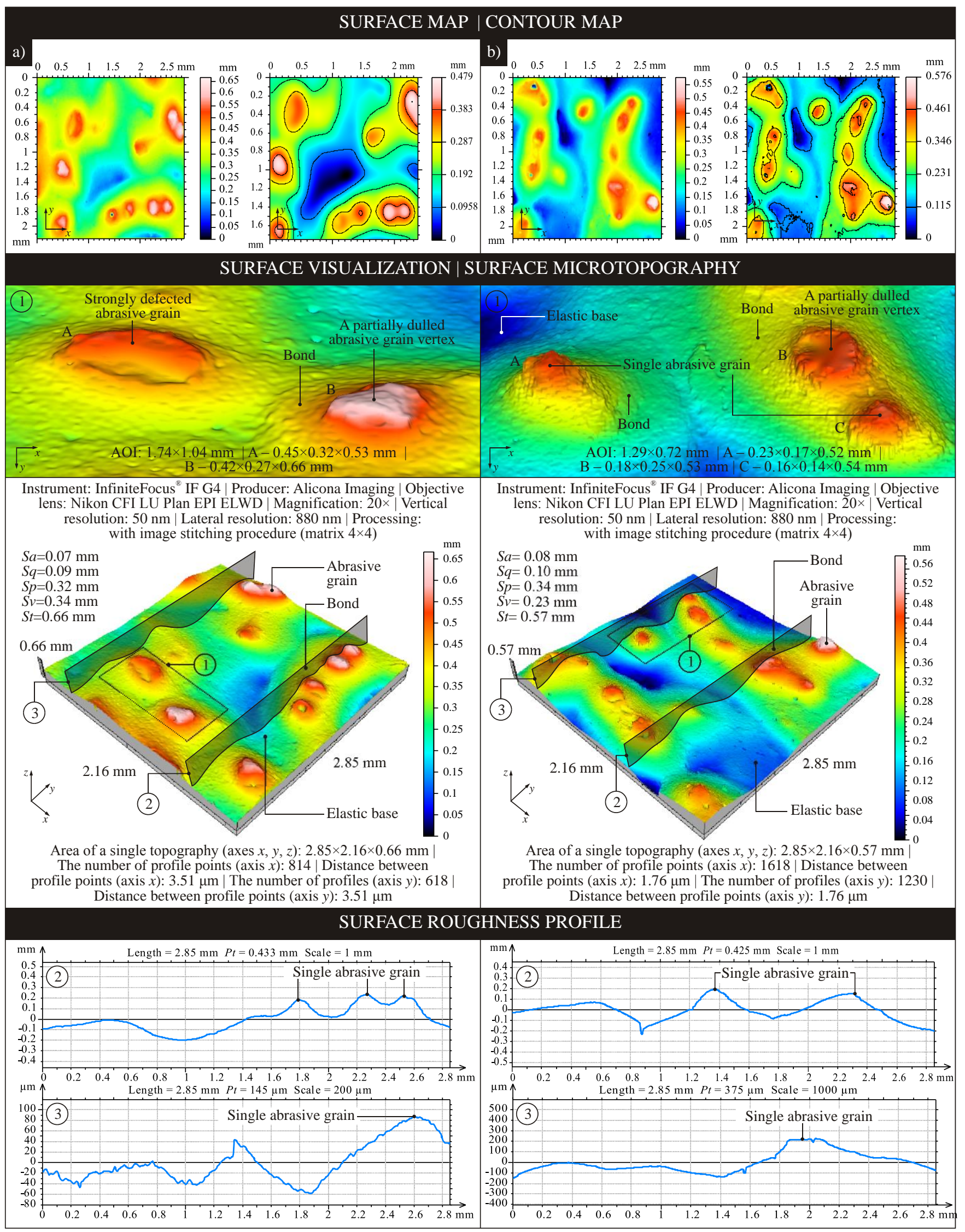

Fig.4. Collection of select results of experimental tests carried out for active surface of abrasive portable belt type $984 \mathrm{~F}$ with Cubitron ${ }^{\mathrm{TM}}$ II grains produced by $3 \mathrm{M}$, obtained by use of focus variation microscope InfiniteFocus ${ }^{\circledR}$ IF G4 produced by Alicona Imaging: a) sequence of results obtained for sample $\mathrm{C} 1-60+$ (grain size: N/A), b) sequence of results obtained for sample C2 - 60+ (grain size: N/A). 

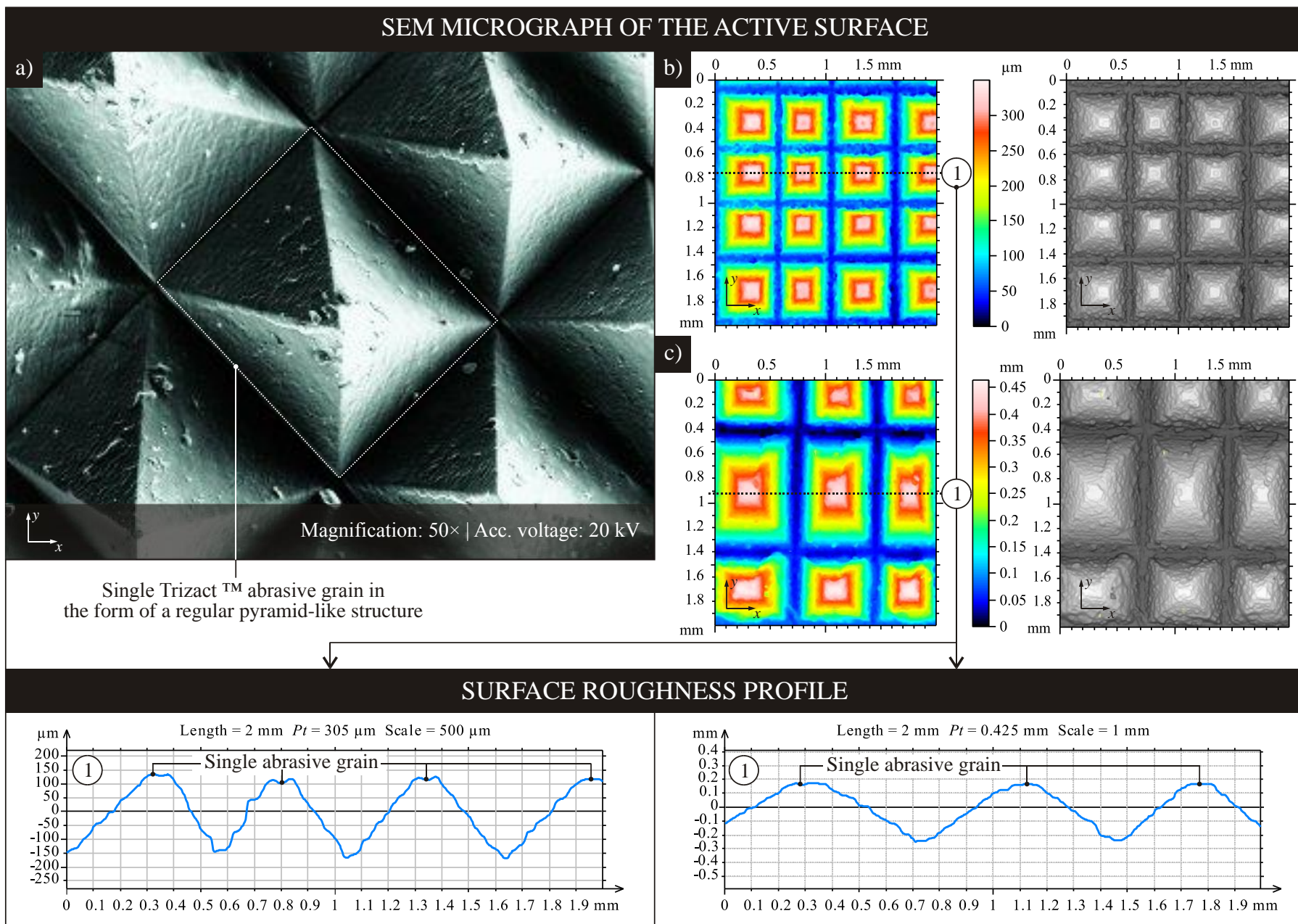

\section{SURFACE MICROTOPOGRAPHY}

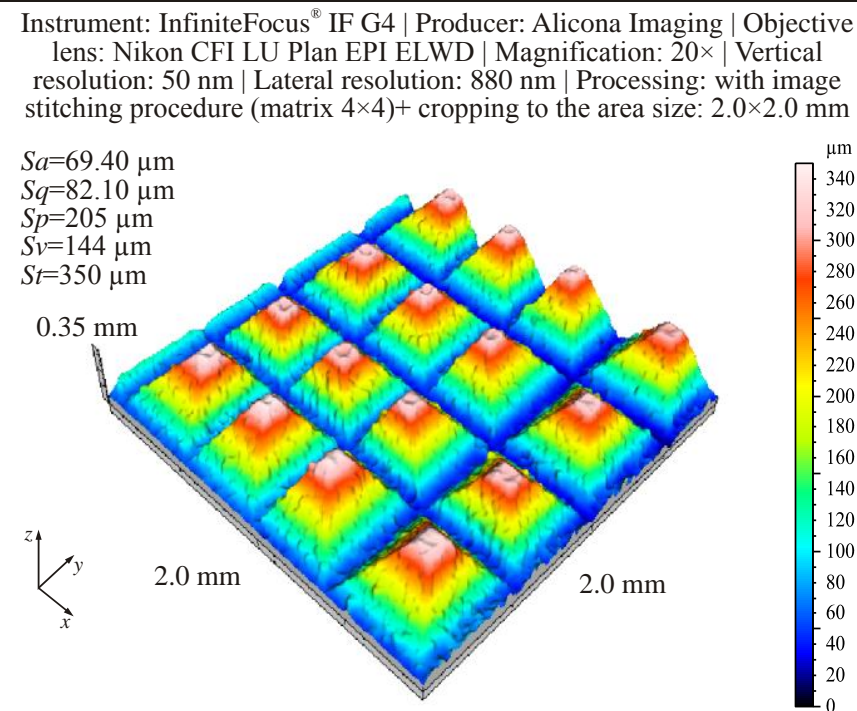

Area of a single topography (axes $x, y, z$ ): $2.0 \times 2.0 \times 0.35 \mathrm{~mm} \mid$ The number of profile points (axis $x$ ): $571 \mid$ Distance between profile points (axis $x$ ): $3.51 \mu \mathrm{m} \mid$ The number of profiles (axis $y$ ): $569 \mid$ Distance between profile points (axis $y$ ): $3.51 \mu \mathrm{m}$
Instrument: InfiniteFocus ${ }^{\circledR}$ IF G4 | Producer: Alicona Imaging | Objective lens: Nikon CFI LU Plan EPI ELWD | Magnification: 20× | Vertical resolution: $50 \mathrm{~nm}$ |Lateral resolution: $880 \mathrm{~nm}$ | Processing: with image stitching procedure (matrix $4 \times 4$ ) + cropping to the area size: $2.0 \times 2.0 \mathrm{~mm}$

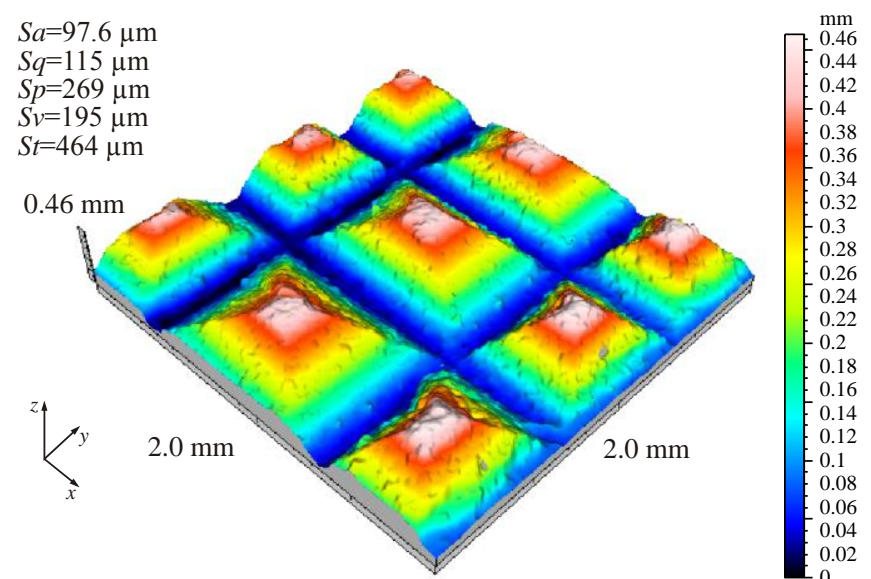

Area of a single topography (axes $x, y, z): 2.0 \times 2.0 \times 0.46 \mathrm{~mm} \mid$ The number of profile points (axis $x$ ): $570 \mid$ Distance between profile points (axis $x$ ): $3.51 \mu \mathrm{m} \mid$ The number of profiles (axis $y$ ): $570 \mid$ Distance between profile points (axis $y$ ): $3.51 \mu \mathrm{m}$

Fig.5. Collection of select results of experimental tests carried out for active surface of single-layer abrasive disc with Trizact ${ }^{\mathrm{TM}}$ grains produced by $3 \mathrm{M}$, obtained by use of focus variation microscope InfiniteFocus ${ }^{\circledR}$ IF G4 produced by Alicona Imaging: a) SEM micrograph presenting the characteristic regular pyramid-like structure of the abrasive tool [40], b) sequence of results obtained for sample T3 - A30 (grain size: $25.8 \mu \mathrm{m}$ ), c) sequence of results obtained for sample T7 - A160 (grain size: $160 \mu \mathrm{m}$ ). 


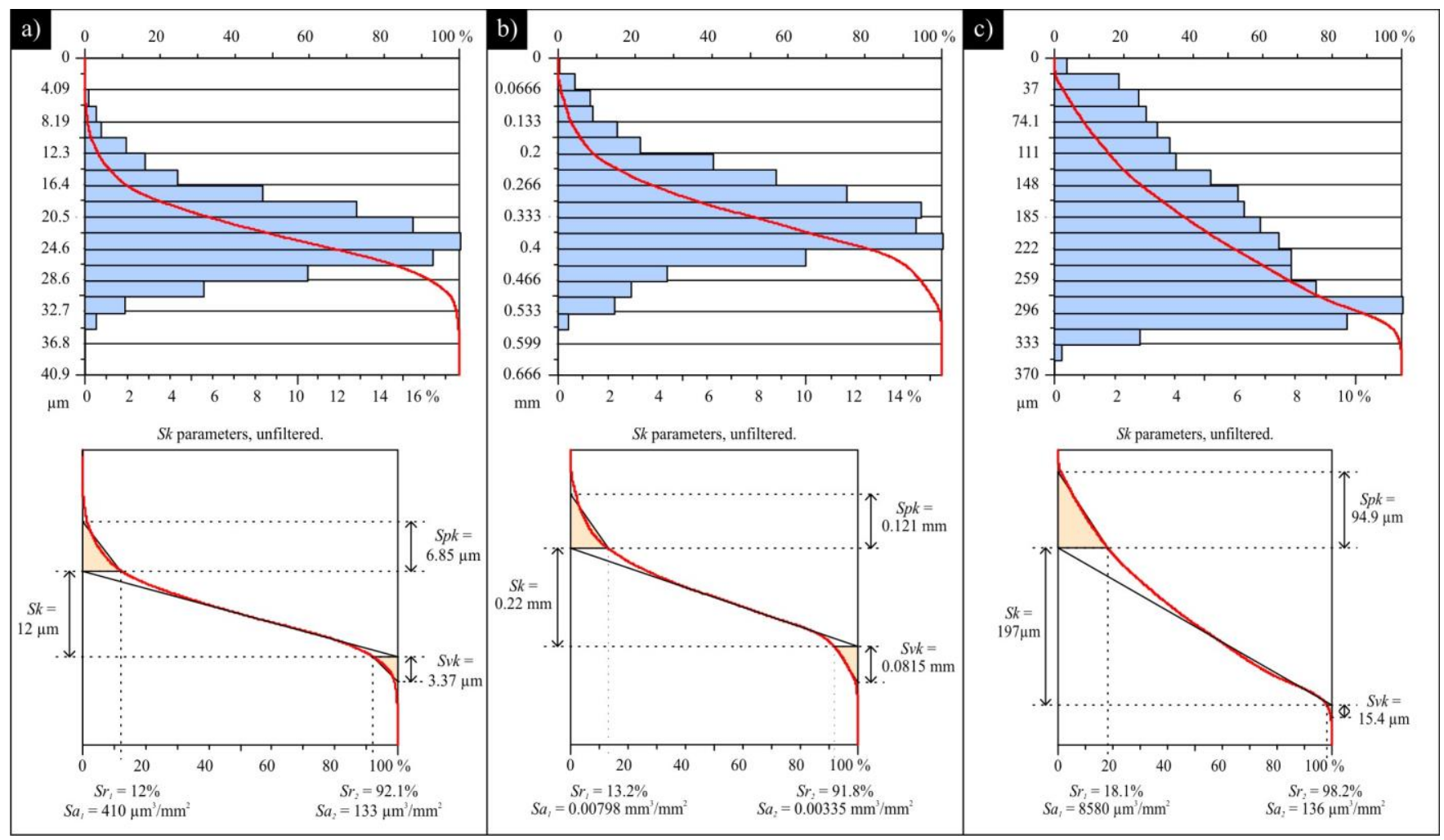

Fig.6. Collection of select results of experimental tests carried out for active surfaces of coated abrasive tools obtained by use of focus variation microscope InfiniteFocus ${ }^{\circledR}$ IF G4 produced by Alicona Imaging - Abbott-Firerstone curves (top) and graphical studies of $S k$ parameters (bottom) for: a) sample F2 - IMMF 600 (grain size: $15 \mu \mathrm{m}$ ), b) sample C1 - 60+ (grain size: N/A), c) sample T3 - A30 (grain size: $25.8 \mu \mathrm{m}$ ).

Table 4. Values of parameters from the amplitude, spatial, hybrid and functional group calculated for example samples.

\begin{tabular}{|c|c|c|c|c|c|c|c|c|}
\hline \multirow{3}{*}{ Group } & \multirow{3}{*}{ Parameter } & \multirow{3}{*}{ Unit } & \multicolumn{6}{|c|}{ Sample } \\
\hline & & & \multicolumn{2}{|c|}{ IMFF (F2) } & \multicolumn{2}{|c|}{ CubitronTM II (C1) $^{\text {TM }}$} & \multicolumn{2}{|c|}{$\operatorname{Trizact}^{\mathrm{TM}}(\mathrm{T3})$} \\
\hline & & & $\begin{array}{l}\begin{array}{c}\text { Average } \\
\text { value }\end{array} \\
\text { valu }\end{array}$ & $\begin{array}{l}\text { Standard } \\
\text { deviation }\end{array}$ & $\begin{array}{c}\text { Average } \\
\text { value }\end{array}$ & $\begin{array}{l}\text { Standard } \\
\text { deviation }\end{array}$ & $\begin{array}{c}\text { Average } \\
\text { value }\end{array}$ & $\begin{array}{l}\text { Standard } \\
\text { deviation }\end{array}$ \\
\hline \multirow{4}{*}{ Amplitude } & $S a$ & $\mu \mathrm{m}$ & 3.85 & 0.379 & 70.91 & 0.022 & 68 & 1.028 \\
\hline & $S q$ & $\mu \mathrm{m}$ & 4.90 & 0.354 & 91.02 & 0.006 & 80.70 & 0.018 \\
\hline & Ssk & - & 0.55 & 0.097 & 0.45 & 0.012 & 0.41 & 0.009 \\
\hline & Sku & - & 3.58 & 0.020 & 3.28 & 0.015 & 3.26 & 0.008 \\
\hline Spatial & $S d s$ & $\mathrm{pks} / \mathrm{mm}^{2}$ & 241 & 18.50 & 121 & 1.650 & 76.7 & 0.110 \\
\hline Hybrid & $S d q$ & - & 1.25 & 0.012 & 1.86 & 0.016 & 1.81 & 0.009 \\
\hline \multirow{3}{*}{ Functional } & $V m p$ & $\mathrm{~mm}^{3} / \mathrm{mm}^{2}$ & 0.002 & 0.0011 & 0.05 & 0.004 & 0.03 & 0.038 \\
\hline & $V m c$ & $\mathrm{~mm}^{3} / \mathrm{mm}^{2}$ & 0.013 & 0.0096 & 0.24 & 0.041 & 0.11 & 0.005 \\
\hline & $V v v$ & $\mathrm{~mm}^{3} / \mathrm{mm}^{2}$ & 0.004 & 0.0039 & 0.09 & 0.0009 & 0.003 & 0.0004 \\
\hline
\end{tabular}

Table 5. Subjective overview of measurement possibilities for selected optical techniques related to the assessment of the active surface of abrasive tool.

\begin{tabular}{|c|l|c|c|c|c|}
\hline \multicolumn{2}{|c|}{ Type of the abrasive tool } & \multicolumn{3}{c|}{ Optical measurement technique } \\
\cline { 3 - 6 } \multicolumn{2}{c|}{} & CLSM & FVM & WLI & OP $($ CCP $)$ \\
\hline \multirow{3}{*}{ Coated } & Elastic microfinishing film IMFF with aluminum oxide grains & $\bullet \bullet \bullet \bullet$ & $\bullet \bullet \bullet$ & $\bullet \bullet \bullet \bullet$ & $\bullet \bullet \bullet$ \\
\cline { 2 - 6 } & Abrasive portable belt with Cubitron ${ }^{\mathrm{TM}}$ II grains & $\bullet \bullet \bullet$ & $\bullet \bullet$ & $\bullet \bullet$ & $\bullet \bullet$ \\
\cline { 2 - 6 } & Single-layer abrasive disc with Trizact ${ }^{\mathrm{TM}}$ grains & $\bullet \bullet$ & $\bullet$ & $\bullet \bullet$ & $\bullet \bullet$ \\
\hline \multirow{3}{*}{ Bonded } & Grinding wheel with CBN grains & $\bullet \bullet$ & $\bullet \bullet$ & $\bullet \bullet$ & $\bullet \bullet$ \\
\cline { 2 - 6 } & Grinding wheel with SG ${ }^{\mathrm{TM}}$ grains & $\bullet$ & $\bullet \bullet$ & $\bullet \bullet \bullet$ & $\bullet$ \\
\cline { 2 - 6 } & Grinding wheel with diamond grains & $\bullet \bullet \bullet \bullet$ & $\bullet \bullet \bullet$ & $\bullet \bullet \bullet \bullet$ & $\bullet \bullet \bullet \bullet$ \\
\hline
\end{tabular}

CLSM - Confocal Laser Scanning Microscopy, FVM - Focus Variation Microscopy, WLI- White-Light Interferometry, OP - Optical profilometry (with confocal chromatic probe), CBN - Cubic Boron Nitride, SG - Microcrystalline Sintered Corundum, measurement of the active surface of abrasive tool: $\bullet \bullet \bullet \bullet-$ very good, $\bullet \bullet \bullet-$ good, $\bullet \bullet-$ sufficiently (acceptable), $\bullet$ - poor (non-acceptable). 


\section{CONCLUSIONS}

On the basis of the measurements and analysis of the active surfaces of a new generation of coated abrasive tools obtained by the use of the FVM technique presented in this paper, the following detailed conclusions can be drawn:

- the proposed measurement technique can be successfully used in measurements and analysis of active surfaces of various-type abrasive tools, also including those which have been described in this paper. FVM is a very promising measurement technique possessing even greater development potential, especially in relation to its hardware (instrumental) implementation. Moreover, it is expected that in a short time, in the span of the next few years, the development of this technique will be still as dynamic as it is now, which will provide the opportunity to introduce the next generation of measuring instruments on the global consumer market;

- the use of an InfiniteFocus ${ }^{\circledR}$ IF G4 focus variation microscope is a modern and advanced measurement technique which is characterized by the following advantages: high measurement efficiency, data resolution, repeatability and traceability, as well as measurement speed, modular and expansible construction with a single measuring head, easy and intuitive operation, dedicated advanced software with a number of useful functions. The disadvantages of this instrument observed during the performed experiments may include: limitations in measurement of surfaces characterized by high angles of slope as the high values of these angles cause considerable difficulties in registering the light beam reflected from the surface being assessed. This situation resulted in the generation of errors in the measurement signal or its complete absence. Indeed, this causes the appearance of non-measured points. In the case of the measurements presented in this paper, the largest number of nonmeasured points was registered for the active surfaces of single-layer abrasive discs with Trizact $^{\mathrm{TM}}$ grains and abrasive portable belts with Cubitron ${ }^{\mathrm{TM}}$ II grains, while the smallest were related to the active surfaces of elastic microfinishing films, type IMFF with aluminum oxide grains;

- relatively low values of selected areal parameters were observed for IMMF samples. These samples were characterized by a strong smoothing of their active surface. For other samples, values of areal parameters were at the same level. This indicates that these surfaces were characterized by a higher angle of slope of the peaks than the surface IMMF sample. This was also confirmed by the structure of abrasive tools with characteristic elements in the form of triangular-shape (Cubitrion $^{\mathrm{TM}}$ II) and regular pyramid-like (Trizact $^{\mathrm{TM}}$ ) abrasive grains;

- measurements of abrasive tools are usually characterized by greater complexity than machined surfaces. In cases of their assessment by the use of optical methods, when the possibilities of carrying out contact (stylus) measurements are strongly limited or cannot be prepared, applying several measurement techniques is recommended. This may be a combination of the methods listed in Table 5. or other accessible methods in the laboratory concerned. Indeed, methods should be selected in such a way as to choose their best metrological characteristics (accuracy, repeatability, traceability and measuring range) for the expected characteristics of assessed surface of the abrasive tool.

\section{ACKNOWLEDGMENTS}

The authors wish to thank the following for providing coated abrasive tools for experimental investigations: Prof. C. Niżankowski, DSc, PhD, ME (Cracow University of Technology, Cracow, Poland), Prof. R. Ściegienka, DSc, $\mathrm{PhD}, \mathrm{ME}$ and J. Baran MSc, BSc, ME (both of Koszalin University of Technology, Koszalin, Poland). Additionally, the authors wish to thank Mr. S. Dubiel (Opole University of Technology, Opole, Poland).

\section{REFERENCES}

[1] Wang, L., Gao, R.X. (Eds.) (2006). Condition Monitoring and Control for Intelligent Manufacturing. Springer.

[2] Wegener, K., Hoffmeister, H.W., Karpuschewski, B., Kuster, F., Hahmann, W.C., Rabiey, M. (2011). Conditioning and monitoring of grinding wheels. CIRP Annals-Manufacturing Technology, 60 (2), 757-777.

[3] Darafon, A., Warkentin, A., Bauer, R. (2013). Characterization of grinding wheel topography using a white chromatic sensor. International Journal of Machine Tools and Manufacture, 70, 22-31.

[4] Yan, L., Rong, Y.M., Jiang, F., Zhou, Z.X. (2011). Three- dimension surface characterization of grinding wheel using white light interferometer. International Journal of Advanced Manufacturing Technology, 55 (14), 133-141.

[5] Rhoney, B.K., Shih, A.J., Scattergood, R.O., Ott, R., McSpadden, S.B. (2002). Wear mechanism of metal bond diamond wheels trued by wire electrical discharge machining. Wear, 252 (7), 644-653.

[6] Qian, J., Li, W., Ohmori, H. (2000). Precision internal grinding with a metal-bonded diamond grinding wheel. Journal of Materials Processing Technology, 105 (1-2), 80-86.

[7] Walter, C., Komischke, T., Kuster, F., Wegener, K. (2014). Laser-structured grinding tools - Generation of prototype patterns and performance evaluation. Journal of Materials Processing Technology, 214 (4), 951-961.

[8] Tian, L., Fu, Y., Xu, J., Li, H., Ding, W. (2015). The influence of speed on material removal mechanism in high speed grinding with single grit. International Journal of Machine Tools and Manufacture, 89, 192201.

[9] Nadolny, K., Kapłonek, W. (2015). Analysis of the effects of the single abrasive-grain microcutting scratch on INCOLOY $^{\circledR}$ alloy $800 \mathrm{HT}^{\circledR}$ by using advanced CLSM-SEM techniques. Proceedings of the Institution of Mechanical Engineers, Part J: Journal of Engineering Tribology, 229 (6), 733-745. 
[10] Hao, X., Pei, S., Wang, L., Xu, H., He, N., Lu, B. (2015). Microtexture fabrication on cylindrical metallic surfaces and its application to a rotor-bearing system. International Journal of Advanced Manufacturing Technology, 78 (5-8), 1021-1029.

[11] von Helmholtz, H.L.F. (1924). Helmholtz's Treatise on Physiological Optics. Optical Society of America.

[12] Leach, R. (Ed.) (2011). Optical Measurement of Surface Topography. Springer.

[13] Helmli, F. (2011). Focus variation instruments. In Optical Measurement of Surface Topography. Springer.

[14] Danzl, R., Helmli, F., Scherer, S. (2011). Focus variation - A robust technology for high resolution optical 3D surface metrology. Strojniški Vestnik Journal of Mechanical Engineering, 57 (3), 245-256.

[15] Helmli, F., Danzl, R., Prantl, M., Grabner, M. (2014). Ultra high speed 3D measurement with the focus variation method. In Fringe $2013: 7^{\text {th }}$ International Workshop on Advanced Optical Imaging and Metrology. Springer.

[16] Subbarao, M., Choi, T. (1995). Accurate recovery of three-dimensional shape from image focus. IEEE Transactions on Pattern Analysis and Machine Intelligence, 17 (3), 266-274.

[17] Moroni, G., Syam, W.P., Petrò, S. (2015). Uncertainty in 3D micro measurement with focus variation microscopy. In Procedings of $10^{\text {th }}$ International Conference on Micromanufacturing (ICMM 2015), Milano, Italy, 1-5.

[18] Tian, Y., Weckenmann, A., Hausotte, T., Schuler, A., He, B. (2013). Measurement strategies in optical 3-D surface measurement with focus variation. In Procedings of $11^{\text {th }}$ International Symposium on Laser Metrology for Precision Measurement and Inspection in Industry (ISCQM 2013), Kraków-Kielce, Poland, 81-85.

[19] Giusca, C.L., Claverley, J.D., Sun, W., Leach, R.K., Helmli, F. Chavigner, M.P. (2014). Practical estimation of measurement noise and flatness deviation on focus variation microscopes. CIRP Annals-Manufacturing Technology, 63 (1), 545-548.

[20] Hiersemenzel, F., Petzing, J.N., Leach, R.K., Helmli, F., Singh, J. (2012). Areal texture and angle measurements of tilted surfaces using focus variation methods. In Proceedings of $3^{\text {rd }}$ International Conference on Surface Metrology (ICSM 2012), Annecy, France, 1-5.

[21] International Organization for Standardization. (2015). Geometrical product specification (GPS) - Surface texture: Areal - Part 606: Nominal characteristics of non-contact (focus variation) instruments. ISO 25178606:2015.

[22] Fujii, M., Kitasako, Y., Sadr, A., Tagami, J. (2011). Roughness and $\mathrm{pH}$ changes of enamel surface induced by soft drinks in vitro-applications of stylus profilometry, focus variation 3D scanning microscopy and micro $\mathrm{pH}$ sensor. Dental Materials Journal, 30 (3), 404-410.

[23] Walton, K., Blunt, L., Fleming, L., Goodhand, M., Lung, H. (2014). Areal parametric characterisation of ex-service compressor blade leading edges. Wear, 321, 79-86.
[24] Nwaogu, U.C., Tiedje, N.S., Hansen, H.N. (2013). A non-contact 3D method to characterize the surface roughness of castings. Journal of Materials Processing Technology, 213 (1), 59-68.

[25] Lim, T.Y., Ratnam, M.M. (2012). Edge detection and measurement of nose radii of cutting tool inserts from scanned 2-D images. Optics and Lasers in Engineering, 50 (11), 1628-1642.

[26] Abdullah, A.B., Sapuan, S.M., Samad, Z., Khaleed, H.M.T., Aziz, N.A. (2012). Geometrical error analysis of cold forged AUV propeller blade using optical measurement method. Journal of Manufacturing Processes, 383, 7117-7121.

[27] Ramdan, R.D., Djuansjah, J.R.P., Suratman, R., Hamzah, E., Sudin, I. (2013). Effect of cold rolling treatment on the formation of titanium oxide layer on Ti6Al4V alloys by thermal-electrochemical anodizing processes. Materials Science Forum, 737, 54-59.

[28] Królczyk, G.M., Niesłony, P., Królczyk, J.B., Samardzic, I., Legutko, S., Hloch, S., Barrans, S., Maruda, R.W. (2015). Influence of argon pollution on the weld surface morphology. Measurement, 70, 203-213.

[29] Niesłony, P., Cichosz, P., Królczyk, G.M., Legutko, S., Smyczek, D., Kołodziej, M. (2016). Experimental studies of the cutting force and surface morphology of explo-sively clad Ti -steel plates. Measurement, 78, 129-137.

[30] Dold, C., Transchel, R., Rabiey, M., Langenstein, P., Jaeger, C., Pude, F., Kuster, F., Wegener, K. (2011). A study on laser touch dressing of electroplated diamond wheels using pulsed picosecond laser sources. CIRP Annals-Manufacturing Technology, 60 (1), 363-366.

[31] Rabiey, M., Dold, C., Transchel, R., Wegener, K. (2011). Influence of picosecond laser touch dressing of electroplated diamond wheels on the dressing of SiC vitrified bond wheel. Advanced Materials Research, 325, 189194.

[32] Weingärtner, E., Roth, R., Kuster, F., Boccadoro, M., Fiebelkorn, F. (2012). Electrical discharge dressing and its influence on metal bonded diamond wheels. CIRP Annals-Manufacturing Technology, 61 (1), 183-186.

[33] Ye, R., Jiang, X., Blunt, L., Cui, C., Yu, Q. (2016). The application of 3D-motif analysis to characterize diamond grinding wheel topography. Measurement, 77, 73-79.

[34] Wang, S., Cui, C., Huan, C., Huang, H., Ye, R. Fu, S. (2013). Stitching for a large area of surface topography analysis of diamond grinding wheel. In Proceedings of SPIE 8759.

[35] Pirisinu, M., Mazzarello, V. (2015). 3D profilometric characterization of the aged skin surface using a skin replica and Alicona Mex software. Scanning, 9999, 1-8.

[36] International Organization for Standardization. (2012). Geometrical product specification (GPS) - Surface texture: Areal - Part 2: Terms, definitions and surface texture parameters. ISO 25178-2:2012.

[37] Stout, K.J. et al. (1993). The Development of Methods for the Characterization of Roughness in Three Dimensions. Publication No. EUR 15178 EN (Final Report) BCR. Brussels, Belgium: European Community. 
[38] Blunt, L, Jiang, X. (2003). Advanced Techniques for the Assessment of Surface Topography: Development of a basis for 3D surface texture standards “SURFSTAND”. London: Kogan Page Science.

[39] Kapłonek, W., Łukianowicz, Cz. (2012). Coherence correlation interferometry in surface topography measurements. In Recent Interferometry Applications in Topography and Astronomy. Rijeka: InTech.
[40] 3M. (2015). Trizact ${ }^{\mathrm{TM}}$ Technology for Paint Finishing. http://3mcollision.com/media/collision-images/miscimages/trizact-grain-detail.jpg

Received December 28, 2015. Accepted March 22, 2016. 